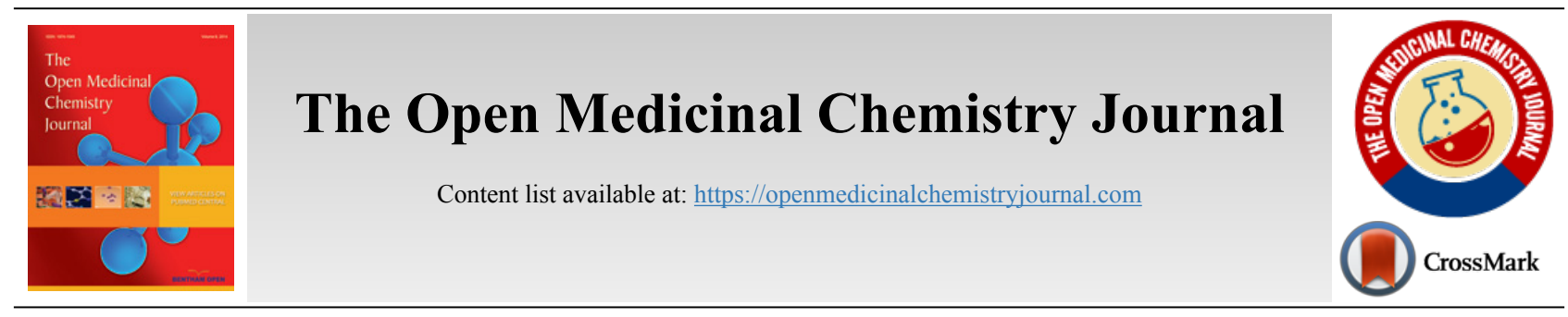

RESEARCH ARTICLE

\title{
Investigation of the Experimental Pharmacokinetics of the Bis-Chlorinated Bis- pyridinium Mono-aldoxime Cholinesterase Reactivator K-868 in Rats
}

\author{
Huba Kalász ${ }^{1}$, Kornélia Tekes ${ }^{2}$, György Bátor ${ }^{3}$, Jennifer Adeghate ${ }^{4}$, Ernest Adeghate ${ }^{5}$, Ferenc Darvas ${ }^{6}$, József Fürész $^{7}$ \\ and Gellért Karvaly,*

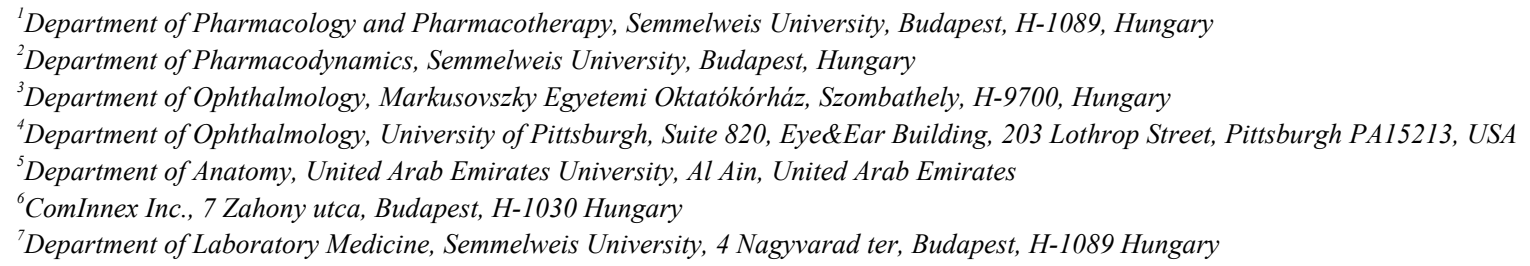

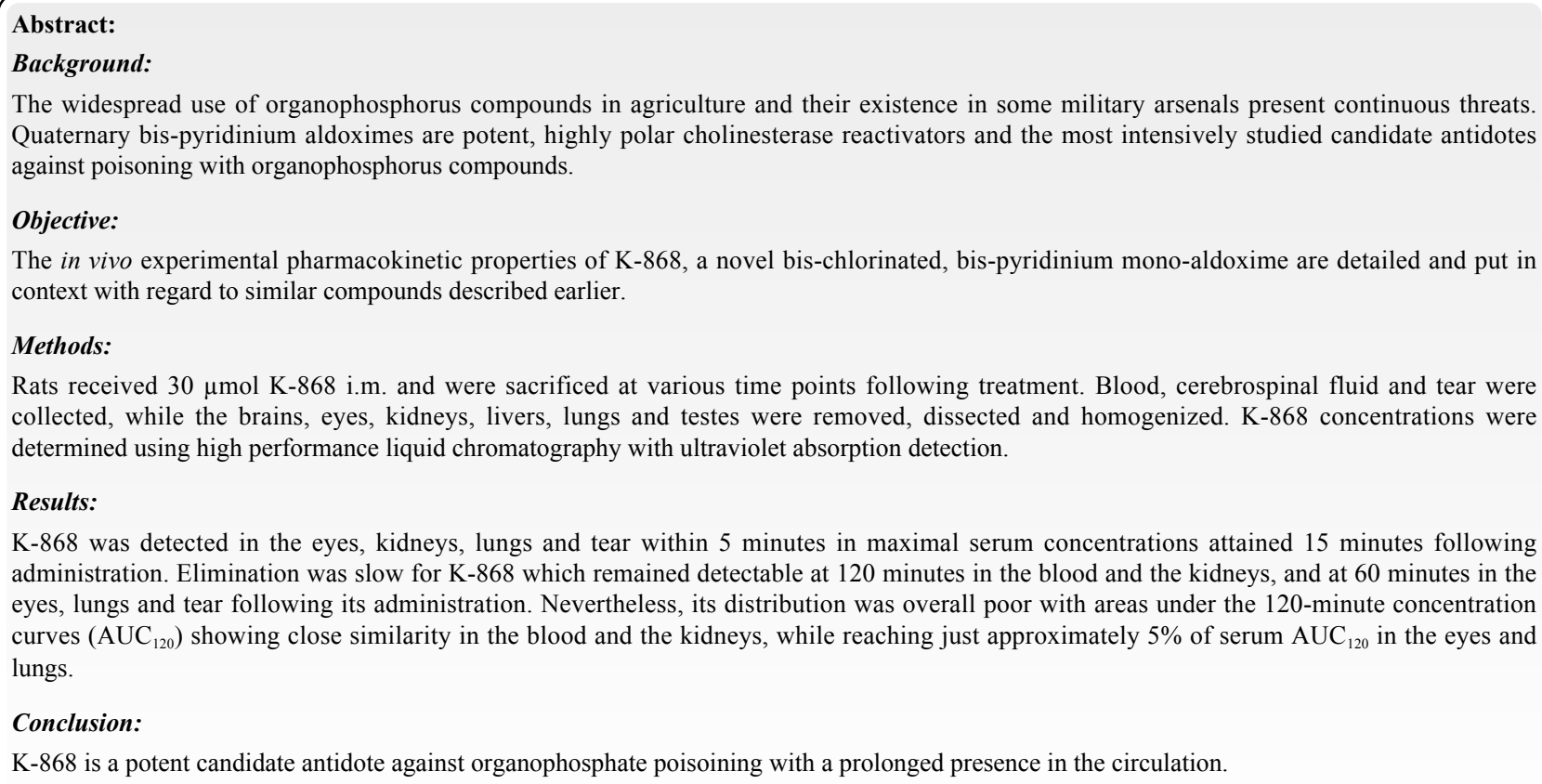

Rats received $30 \mu \mathrm{mol}$ K-868 i.m. and were sacrificed at various time points following treatment. Blood, cerebrospinal fluid and tear were collected, while the brains, eyes, kidneys, livers, lungs and testes were removed, dissected and homogenized. K- 868 concentrations were determined using high performance liquid chromatography with ultraviolet absorption detection.

Results:

K-868 was detected in the eyes, kidneys, lungs and tear within 5 minutes in maximal serum concentrations attained 15 minutes following administration. Elimination was slow for K-868 which remained detectable at 120 minutes in the blood and the kidneys, and at 60 minutes in the eyes, lungs and tear following its administration. Nevertheless, its distribution was overall poor with areas under the 120-minute concentration curves $\left(\mathrm{AUC}_{120}\right)$ showing close similarity in the blood and the kidneys, while reaching just approximately $5 \%$ of serum $\mathrm{AUC} \mathrm{C}_{120}$ in the eyes and lungs.

Conclusion:

$\mathrm{K}-868$ is a potent candidate antidote against organophosphate poisoining with a prolonged presence in the circulation.

Keywords: Pharmacokinetics, K-868, Pyridinium aldoxime, Blood-brain barrier, Organophosphate poisoning, Cholinesterase.

\begin{tabular}{|l|l|l|l|}
\hline Article History & Received: June 10, 2021 & Revised: September 03, 2021 & Accepted: October 28, 2021
\end{tabular}

\section{INTRODUCTION}

Organophosphorus compounds are used worldwide as pesticides and insecticides with acceptable safety margins

\footnotetext{
* Address correspondence to this author at the Department of Laboratory Medicine, Semmelweis University, H-1089 Budapest, Nagyvárad tér 4, Hungary; Tel: +36208259819; E-mail: karvaly.gellert_balazs@med.semmelweis-univ.hu
}

when handled properly. Nevertheless, personnel working with these agents are subjected to acute and chronic occupational intoxication with frequently recurring suicidal poisonings [1, 2]. In addition, recent events have shown that the existence of organophosphorus chemical warfare agents continues to present a threat $[3-6]$. Symptoms are generated by the inhibition of cholinesterase enzymes, most importantly that of 
acetylcholinesterase (AChE, EC 3.1.1.7), both in the central and the peripheral nervous systems, leading to toxic elevations in acetylcholine levels, to respiratory failure and, in severe cases, death [7]. While repeated contact is the most prevalent cause of intoxication, severe symptoms have been reported among the survivors of single high dose exposures.

The treatment of intoxication still presents a medical challenge. AFLOP therapy (the key elements of which are the muscarinic receptor antagonist atropine - competing with acetylcholine for the receptor -, fluids and oxygen to prevent hypotension and respiratory failure, and also pyridinium aldoxime cholinesterase reactivators such as pralidoxime or obidoxime) has become the standard treatment for acute intoxication (Table 1) [5, 8].

Cholinesterase reactivators have the unique ability to cleave the covalent bond formed between the organophosphorus toxicant and the serine hydroxyl group located at the active site of the cholinesterase enzyme eventually restoring acetylcholinesterase activity. Clinical evidence suggests that the importance of studying the pharmacodynamic and pharmacokinetic properties of acetylcholinesterase reactivators has not diminished. The monopyridinium aldoxime pralidoxime penetrates through the blood-brain barrier but is very rapidly eliminated from the bloodstream [9 - 12]. Kuca et al. synthesized several bis- pyridinium aldoximes that have reactivation potencies similar to those of pralidoxime and obidoxime but show improved pharmacokinetic properties [13 - 18]. Some experimental substances are also highly capable of reversing the quick aging of bonds formed between cholinesterases and chemical warfare agents such as tabun [19].

Following their intramuscular administration to rats, an important unfavourable property of many bispyridinium aldoxime structures is the rapid decrease in circulating concentrations. The development of a slowly eliminated candidate antidote has therefore been ambitioned [20]. Examples of scouted compounds are K-117, K-127, K-203, $\mathrm{K}-867$, and K-870 [13, 21, 22].

Our preliminary results regarding the pharmacokinetic properties of the first bis-chlorinated bis-pyridinium bisaldoxime K-868 [4-carbamoyl-1-(4-\{3,5-dichloro-4-[(hydroxyimino) methyl] pyridinium-1-yl $\}$ propyl) pyridinium dibromide] are presented in this paper. Chlorinated compounds have been essential in medical care, from local disinfection through cancer treatments to the modulation of the activity of the central nervous system. Accordingly, prescription drugs containing two chlorine atoms have widely been used in human therapy, as demonstrated previously [23]. K-868 showed excellent in vitro reactivation ability to butyrylcholinesterase (BuChE) inhibited by various nerve gases [24].

Table 1. Chemical structures, logP values and topological polar surface areas (TPSA) of relevant pyridinium aldoximes.

\begin{tabular}{|c|c|c|c|c|}
\hline Compound & Chemical Structure & Analytical \&onditions & $\log P$ & $\begin{array}{c}\text { TPSA } \\
\left(\AA^{2}\right)\end{array}$ \\
\hline $\begin{array}{c}\mathrm{K}-27 \\
{[10,27]}\end{array}$ & $\mathrm{HO}$ & $\begin{array}{c}\text { Stationary phase: } \\
\text { Zorbax Rx-C18 }(250 \times 4.6 \mathrm{~mm}, 5 \mu \mathrm{m}) \\
\text { Mobile Phase: acetonitrile:aqueous buffer }\left(56.2 \mathrm{mmol} / \mathrm{L} \mathrm{Na}_{2} \mathrm{HPO}_{4} \text {, }\right. \\
47.9 \mathrm{mmol} / \mathrm{L} \text { citric acid, } 0.027 \mathrm{mmol} / \mathrm{L} \text { EDTA, } 0.925 \mathrm{mmol} / \mathrm{L} \\
\text { octanesulphonic acid, } 0.1 \mathrm{~mol} / \mathrm{L} \text { diethylamine, } 0.2 \mathrm{~mol} / \mathrm{L} \mathrm{phosphoric} \\
\text { acid, } 2 \mathrm{mmol} / \mathrm{L} \text { octane sulfonic acid }) 75: 950\end{array}$ & -7.82 & 85.47 \\
\hline $\begin{array}{c}\text { K-48 } \\
{[28]}\end{array}$ & $2 \mathrm{Br}$ & $\begin{array}{c}\text { Stationary phase: } \\
\text { Supelco C8 }(250 \times 4.6 \mathrm{~mm}, 5 \mu \mathrm{m}) \\
\text { Mobile phase: } 15 \mathrm{mmol} / \mathrm{L} \text { phosphate buffer, } \mathrm{pH}=2.6: \text { methanol } 95: 5\end{array}$ & -7.63 & 83.47 \\
\hline $\begin{array}{c}\mathrm{K}-203 \\
{[14,22,26]}\end{array}$ & & $\begin{array}{l}\text { Stationary phase: Zorbax RxC18 }(250 \times 4.6 \mathrm{~mm}, 5 \mu \mathrm{m}) \\
\text { Mobile Phase: buffer }(0.1 \mathrm{~mol} / \mathrm{L} \text { diethylamine, } 0.2 \mathrm{~mol} / \mathrm{L} \text { phosphoric } \\
\text { acid, } 2 \mathrm{mmol} / \mathrm{L} \text { sodium octanesulfonate):acetonitrile } 95: 5\end{array}$ & -7.88 & 83.44 \\
\hline K-867 [13] & 2 & $\begin{array}{c}\text { Stationary phase: } \\
\text { Phenomenex Kinetex EVO-C18 }(100 \times 3 \mathrm{~mm}, 5 \mu \mathrm{m}) \\
\text { Mobile Phase: aqueous buffer [sodium acetate }(5.44 \mathrm{~g} / \mathrm{L} \text {, citric acid } \\
(4.72 \mathrm{~g} / \mathrm{L} \text {, sodium octanesulfonate }(2 \mathrm{~g} / \mathrm{L})]: \text { acetonitrile:methanol } \\
80: 10: 10\end{array}$ & -6.78 & 83.44 \\
\hline K-868 [20] & $2 \mathrm{Br}$ & $\begin{array}{c}\text { Stationary phase: } \\
\text { Phenomenex Kinetex EVO-C18 }(100 \times 3 \mathrm{~mm}, 5 \mu \mathrm{m}) \\
\text { Mobile Phase: aqueous buffer [sodium acetate }(5.44 \mathrm{~g} / \mathrm{L} \text {, citric acid } \\
(4.72 \mathrm{~g} / \mathrm{L} \text {, sodium octanesulfonate }(2 \mathrm{~g} / \mathrm{L})] \text { :acetonitrile:methanol } \\
80: 10: 10\end{array}$ & -7.23 & 83.44 \\
\hline
\end{tabular}


(Table 1) contd.....

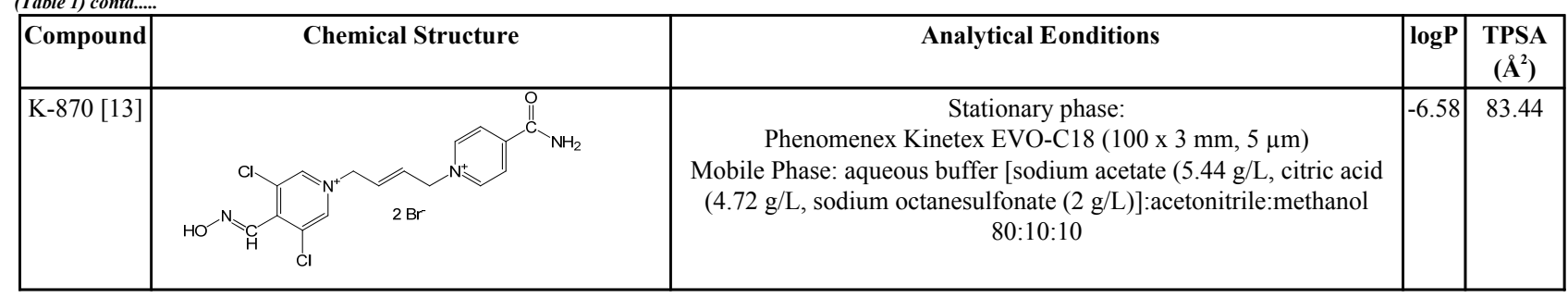<smiles>NC(=O)c1cc[n+](CCC[n+]2cc(Cl)c(/C=N/O)c(Cl)c2)cc1Br</smiles>

K-868<smiles>O/N=C\c1cccc[n+]1Cc1ccccc1</smiles>

K-347

Fig. (1). Structural formulas of K-868 and the internal standard K-347.

Reversed-phase ion-pair high performance liquid chromatography with ultraviolet absorbance detection (RP-IPHPLC-UV) has proved to be superior in applicability and costefficiency [10, 12, 13, 20, 24 - 26]. The preparation of solid organ and tissue homogenate samples, as well as bodily fluids, can be performed in a straightforward manner by adding diluted aqueous trichloroacetic acid or perchloric acid to the samples and vortexing the mixtures, followed by centrifugation and the separation of the supernatant [20 - 27].

The objectives of the presented work were (1) to provide a preliminary description of the pharmacokinetics of K-868 in serum in vivo, and (2) to investigate its penetration into liquor, as well as into peripheral organs and fluid spaces, an important task for the assessment of the antidotal effects as well as the toxicity of this substance.

\section{MATERIALS AND METHODS}

\subsection{Chemicals, Solvents, and Materials}

The target compound K-868 and the internal standard K-347 (1-benzyl-2-hydroxyiminomethylpyridinium bromide) were synthesized in the Department of Chemistry, University of Hradec Kralove, Czech Republic. The chemical structures of both substances are shown in Fig. (1). All solvents and chemicals employed were of at least HPLC grade.

\subsection{Physical and Analytical Characterization of K-868 and K-347}

The physical properties of K-868 and the internal standard $\mathrm{K}-347$ were characterized by measuring their melting points using a Büchi Melting Point B-540 apparatus at the Department of Organic Chemistry, Semmelweis University, Budapest, as well as by recording the product ion mass spectra of the pseudomolecular ions $\mathrm{m} / \mathrm{z}=177$ and $\mathrm{m} / \mathrm{z}=213$, respectively. The mass spectrometry experiments were performed using a Shimadzu Nexera X2 ultra-high performance liquid chromatography coupled to a Shimadzu LCMS-8050 triple quadrupole mass spectrometer (Simkon
Kft., Budapest, Hungary) operated in the positive electrospray ionization mode and by applying a flow injection analysis method. The analytes were introduced as aqueous solutions, with the concentrations of K-868 and K-347 being $805 \mathrm{ng} / \mathrm{ml}$ and $88.2 \mathrm{ng} / \mathrm{ml}$, respectively. The mobile phase was a $1: 1$ mixture of water and methanol, both containing $0.1 \%$ formic acid. The mobile phase flow rate was $0.2 \mathrm{~mL} / \mathrm{min}$. The following mass spectrometer settings were employed: electrode voltage: $+4000 \mathrm{~V}$, nebulizer gas: $3 \mathrm{~L} / \mathrm{min}$, drying gas: $5 \mathrm{~L} / \mathrm{min}$, heating gas: $8 \mathrm{~L} / \mathrm{min}$, interface temperature: $250{ }^{\circ} \mathrm{C}$, heating block temperature: $250{ }^{\circ} \mathrm{C}$, desolvation line temperature: 230 ${ }^{\circ} \mathrm{C}$. Argon 5.0 (Messer Hungarogáz Kft., Budapest, Hungary) was applied as the collision induced dissociation gas at a pressure of $270 \mathrm{kPa}$. The product ion mass spectra of K-868 and $\mathrm{K}-347$ were recorded in the mass ranges $\mathrm{m} / \mathrm{z}=50-200$ and $\mathrm{m} / \mathrm{z}=50-220$, respectively.

\subsection{Animals and Treatment}

All steps of animal handling, treatment procedures, and sample preparation conformed to the 2010/63/EU regulation on the well-being of experimental animals and were done according to the permission of the Local Committee of Animal Welfare (Permission Number: PE/EA/385-7/2018). 30 male Wistar rats were purchased from Toxicoop Kft. (Budapest, Hungary). Following an acclimatization period $(24 \mathrm{~h})$, the animals were administered $0.2 \mathrm{~mL}$ of a freshly prepared sterile aqueous solution containing $30 \mu \mathrm{mol} \mathrm{K}-868(150 \mu \mathrm{mol} / \mathrm{mL})$ as an intramuscular (i.m.) bolus injection into the m.biceps femoris. The weight of the six-week-old animals was $190 \pm 10 \mathrm{~g}$ at the time of their use. Due to the narrow range of body weight, the employed dose was not normalized. Three independent experiments were conducted, each with 10 animals. In the first two experiments, concentrations of K-868 were evaluated in the serum and in brain homogenates. In the third experiment, cerebrospinal fluid, tear, and further solid organs (eyes, kidneys, liver, lungs, and testes) were also processed. Tear samples were first drawn without applying anaesthesia. Liquor was collected after keeping the animal in a chamber filled with diethyl ether aerosol for $15 \mathrm{~s}$. 
Subsequently, general anesthesia with diethyl ether was applied until death. Exsanguination into a $15-\mathrm{mL}$ polypropylene centrifuge tube was performed via the campus, followed by the removal of solid organs. Two animals were sacrificed at each of the following sampling times: 5, 15, 30, 60, and $120 \mathrm{~min}$ post-treatment ( $\mathrm{n}=2$ at each). Blood samples were centrifuged at $14000 \mathrm{x}$ g for $10 \mathrm{~min}$, and the serum was separated. Solid organs were dissected immediately and kept at $-80^{\circ}$ until being processed. Blood was not removed from the solid organs prior to their homogenization.

\subsection{Sample Preparation}

Wet solid tissue samples of approximately $200 \mathrm{mg}$ were weighed on an analytical balance and were homogenized by adding a fourfold volume of $0.3 \mathrm{~mol} / \mathrm{L}$ perchloric acid aqueous solution and the internal standard K-347 by an Ultra Turrax T25 Janke\&Kunkel homogenizer (IKA Labortechnik, Staufen, Germany) at $20,000 \times \mathrm{g}$ for $30 \mathrm{~s}$ at room temperature. The homogenates were centrifuged at $14,000 \mathrm{xg}$ for $20 \mathrm{~min}$ at $4{ }^{\circ} \mathrm{C}$. Liquor and tear were diluted with a fourfold, while serum was diluted with a ninefold excess of $0.3 \mathrm{~mol} / \mathrm{L}$ perchloric acids containing the internal standard, followed by vortexing, centrifugation at $14000 \mathrm{xg}$ for $10 \mathrm{~min}$, and the separation of the supernatant, which was submitted to HPLC-RP-IP-UV analysis.

$\mathrm{K}-347$ was spiked to liquid samples at $1.0 \mu \mathrm{g} / \mathrm{mL}(3.41$ $\mu \mathrm{mol} / \mathrm{L})$, and to solid samples at $1.0 \mu \mathrm{g} / \mathrm{g}(3.41 \mu \mathrm{mol} / \mathrm{g})$. Calibration was performed by analyzing the $0.3 \mathrm{~mol} / \mathrm{L}$ perchloric acid solutions of K-868 at $0.097,0.194,0.388$, $0.971,1.94,6.47$, and $19.4 \mu \mathrm{mol} / \mathrm{L}$ in 2 replicates. The same analytical method was employed for all investigated bodily fluids and solid organs.

\subsection{Analysis}

The analytical equipment (JASCO 4000 series) contained the following modules: a pump (PU-4180), a sample introduction unit (AS-4050), and a photodiode array detector (MD-4010). The analytical column was thermostatted at $35^{\circ}$. JASCO ChromNav 2.0 software was employed for data acquisition and instrument control (ABL\&E-JASCO Hungary Ltd, Budapest, Hungary). K-347 was used as an internal standard.

$\mathrm{K}-868$ and $\mathrm{K}-347$ were chromatographed in isocratic runs. A Phenomenex Kinetex EVO-C18 100x3 mm column (particle size: $5 \mu \mathrm{m}$ ), thermostatted at $40{ }^{\circ} \mathrm{C}$, was used as stationary phase (Gen-Lab Kft., Budapest, Hungary). The mobile phase contained an aqueous buffer solution, methanol, and acetonitrile $(80: 10: 10, \mathrm{v} / \mathrm{v})$. The buffer solution consisted of citric acid $(4.7 \mathrm{~g} / \mathrm{L})$, sodium acetate $(5.4 \mathrm{~g} / \mathrm{L})$, and sodium 1octanesulfonate $(2.0 \mathrm{~g} / \mathrm{L})$. The injected sample volume was 50 $\mu \mathrm{L}$, and the run time was $10 \mathrm{~min}$. K-868 and $\mathrm{K}-347$ were evaluated at $300 \mathrm{~nm}$ absorption wavelength.

\subsection{Data Evaluation}

K-868 and the internal standard K-347 were identified by their retention times. Quantitative evaluation was based on analyte/internal standard peak area ratios. Samples were measured in quintuplicates. The calibrated analyte range was $0.097-19.4 \mu \mathrm{mol} / \mathrm{L}$ (corresponding to $0.971-194 \mu \mathrm{mol} / \mathrm{L}$ in serum and to $0.388-77.6 \mu \mathrm{mol} / \mathrm{g}$ in liquor, tear, and in solid tissues). The calibration model was obtained by applying least squares linear regression using $1 / \mathrm{x}^{2}$ weights. 120 -minute areas under the concentration-time curves $\left(\mathrm{AUC}_{120}\right)$ were calculated using the trapezoid method and a microsoft excel spreadsheet.

The full validation of the analytical method was performed using rat serum as described earlier [25]. The limit of detection was $0.039 \mu \mathrm{mol} / \mathrm{L}$. The lowest-level calibrator was considered as the lower limit of quantitation. Based on the evaluation of 4 concentration levels in 6 independent matrices, the within-run accuracy and precision were $97.9-110 \%$ and $8.71-12.0 \%$ in serum, respectively. The between-run accuracy and precision were $95.5-117.3 \%$ and $1.6-20.0 \%$, respectively, as established in serum by running 4 samples spiked with K-868 at 4 different concentration levels. While it is crucial to perform the full validation of the methodology for peripheral tissues in future studies conducted with the scope of the quantitative assessment of the pharmacokinetic parameters of K-868, the aim at this early stage of research was to scout the range of organs penetrated by K-868, and such an extensive method validation was not performed.

\section{RESULTS}

The melting points of the bromide salts of K-868 and K-347 were $214.7-216.1{ }^{\circ} \mathrm{C}$ and $203.2-204.3{ }^{\circ} \mathrm{C}$, respectively. The full scan and product ion mass spectra of the pseudomolecular ions $\mathrm{m} / \mathrm{z}=177(\mathrm{~K}-868)$ and $\mathrm{m} / \mathrm{z}=213(\mathrm{~K}-347)$ are shown in Fig. (2). The properties of K-347 have been discussed in more detail in earlier publications [20, 28, 29].

The chromatographic separation of K-868 and K-347 is shown in Fig. (3). The employed method was selective, with no interferences obtained at the retention times of the analyte or the internal standard ( 9.1 and $6.8 \mathrm{~min}$, respectively). A representative calibration plot is displayed in Fig. (4).

The time-dependence of the course of K-868 concentrations in serum, kidneys, lungs, eye, and tear are shown in (Fig. 5 and Table 2). K-868 entered the systemic circulation and distributed into the kidneys, lungs, and tear almost instantaneously, appearing in all samples collected 5 minutes after its administration. The peak blood concentrations were reached by 15 or $30 \mathrm{~min}$. K-868 concentrations in the serum and the kidneys were similar, and the substance could be quantitated up to $120 \mathrm{~min}$ in both. K-868 appeared in the lungs and the eyes between up to $60 \mathrm{~min}$ postdose. Tear contained $\mathrm{K}-868$ in low concentrations already at $5 \mathrm{~min}$ and could be for $30-60 \mathrm{~min}$. The compound was detected only in 10 of the 30 brain homogenate samples, and even in these, its concentration was lower than the limit of quantitation. K-868 could not be detected in the cerebrospinal fluid, the liver, or the testes.

The calculated 120-minute areas under the concentrationtime curve $\left(\mathrm{AUC}_{0-120}\right)$ indicated virtually identical exposure to $\mathrm{K}-868$ in serum and in the kidneys. $\mathrm{AUC}_{0-120}$ values observed in the lungs and in the eyes were more than a magnitude lower, while the amount of substance found in a tear was negligible (Table 3). 

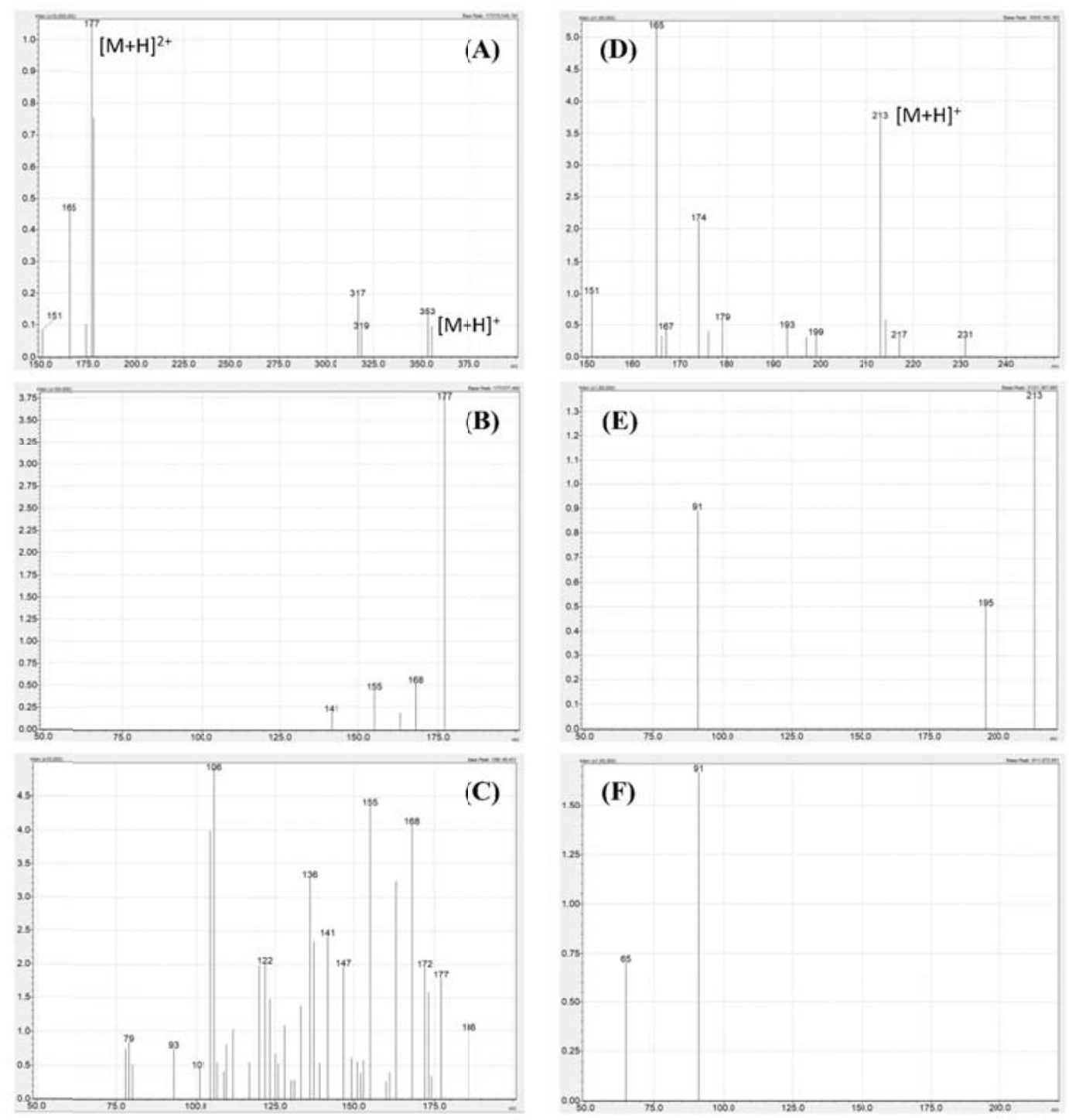

Fig. (2). Positive electrospray ionization product ion mass spectra of K-868 and K-347. (A) full positive scan mass spectrum of K-868, (B) positive product ion mass spectrum of K-868 (collision energy: $-10 \mathrm{~V}$ ), (C) positive product ion mass spectrum of K-868 (collision energy: $-20 \mathrm{~V}$ ), (D) full positive scan mass spectrum of K-347, (E) positive product ion mass spectrum of K-347 (collision energy: -10 V), (F) positive product ion mass spectrum of K-347 (collision energy: $-40 \mathrm{~V}$ ).

Table 2. K-868 concentrations obtained in the performed experiments.

\begin{tabular}{|c|c|c|c|c|c|}
\hline \multicolumn{6}{|c|}{$\operatorname{Serum}(\mu \mathrm{mol} / \mathrm{L})$} \\
\hline \multirow{2}{*}{ Experiment } & \multicolumn{5}{|c|}{ Time from Dose Administration } \\
\hline & $5 \mathrm{~min}$ & $15 \mathrm{~min}$ & $30 \mathrm{~min}$ & $60 \mathrm{~min}$ & $120 \mathrm{~min}$ \\
\hline 1 & 29.6 & 63.0 & 30.3 & 17.4 & 6.5 \\
\hline 2 & 47.9 & 49.5 & 48.8 & 17.5 & 7.6 \\
\hline 3 & 44.8 & 19.3 & 28.5 & 14.5 & 4.4 \\
\hline 4 & 45.8 & 53.0 & 27.6 & 15.1 & 5.2 \\
\hline 5 & 65.6 & 64.0 & 59.5 & 36.1 & 5.0 \\
\hline 6 & 78.8 & 80.1 & 57.0 & 28.2 & 7.2 \\
\hline \multicolumn{6}{|c|}{ Kidney $(\mu \mathrm{mol} / \mathrm{g})$} \\
\hline 1 & 23.3 & 77.5 & 46.4 & 11.6 & 6.6 \\
\hline 2 & 45.2 & 51.6 & 59.8 & 17.6 & 5.4 \\
\hline
\end{tabular}


(Table 2) contd...

\begin{tabular}{|c|c|c|c|c|c|}
\hline \multicolumn{6}{|c|}{ Serum $(\mu \mathrm{mol} / \mathrm{L})$} \\
\hline \multirow{2}{*}{ Experiment } & \multicolumn{5}{|c|}{ Time from Dose Administration } \\
\hline & $5 \mathrm{~min}$ & $15 \mathrm{~min}$ & $30 \mathrm{~min}$ & $60 \mathrm{~min}$ & $120 \mathrm{~min}$ \\
\hline \multicolumn{6}{|c|}{ Lung $(\mu \mathrm{mol} / \mathrm{g})$} \\
\hline 1 & 1.78 & 3.92 & 1.18 & 0.9 & $<0.1$ \\
\hline 2 & 2.52 & 2.02 & 3.25 & 1.16 & $<0.1$ \\
\hline \multicolumn{6}{|c|}{ Eye $(\mu \mathrm{mol} / \mathrm{g})$} \\
\hline 1 & 0.412 & 1.2 & 1.23 & 0.77 & $<0.1$ \\
\hline 2 & 1.72 & 2.35 & 3.46 & 1.12 & $<0.1$ \\
\hline \multicolumn{6}{|c|}{ Tear $(\mu \mathrm{mol} / \mathrm{L})$} \\
\hline 1 & 0.6 & 0.3 & 0.4 & $<0.1$ & 0.6 \\
\hline 2 & 0.8 & 0.4 & $<0.1$ & $<0.1$ & 0.8 \\
\hline
\end{tabular}
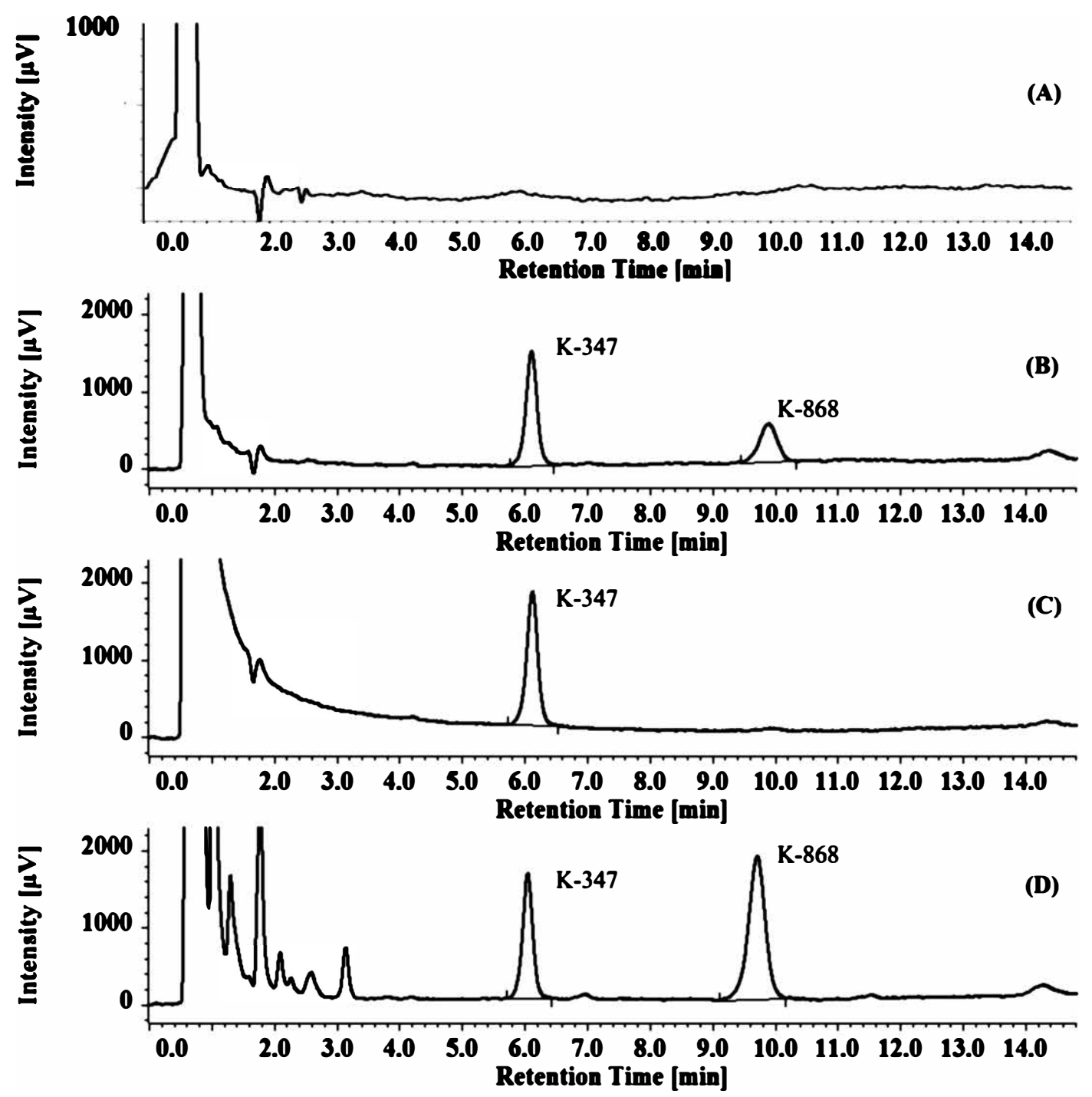

(3) Chromatographic separation of K-868 using high performance liquid chromatography-ultraviolet absorbance detection at $300 \mathrm{~nm}$. (A) (1) internal standard K-347 (K-868: 1.94 Chromatogram of a blank solvent sample, (B) chromatogram of a stan sample spiked with the internal standard (3.41 $\mu$ mol/L), (D) chromatogram of $\mu \mathrm{mol} / \mathrm{L}, \mathrm{K}-347: 3.41 \mu \mathrm{mol} / \mathrm{L}$ ), (C) chromatogram of a blank rat serum sample spiked withe a rat serum 


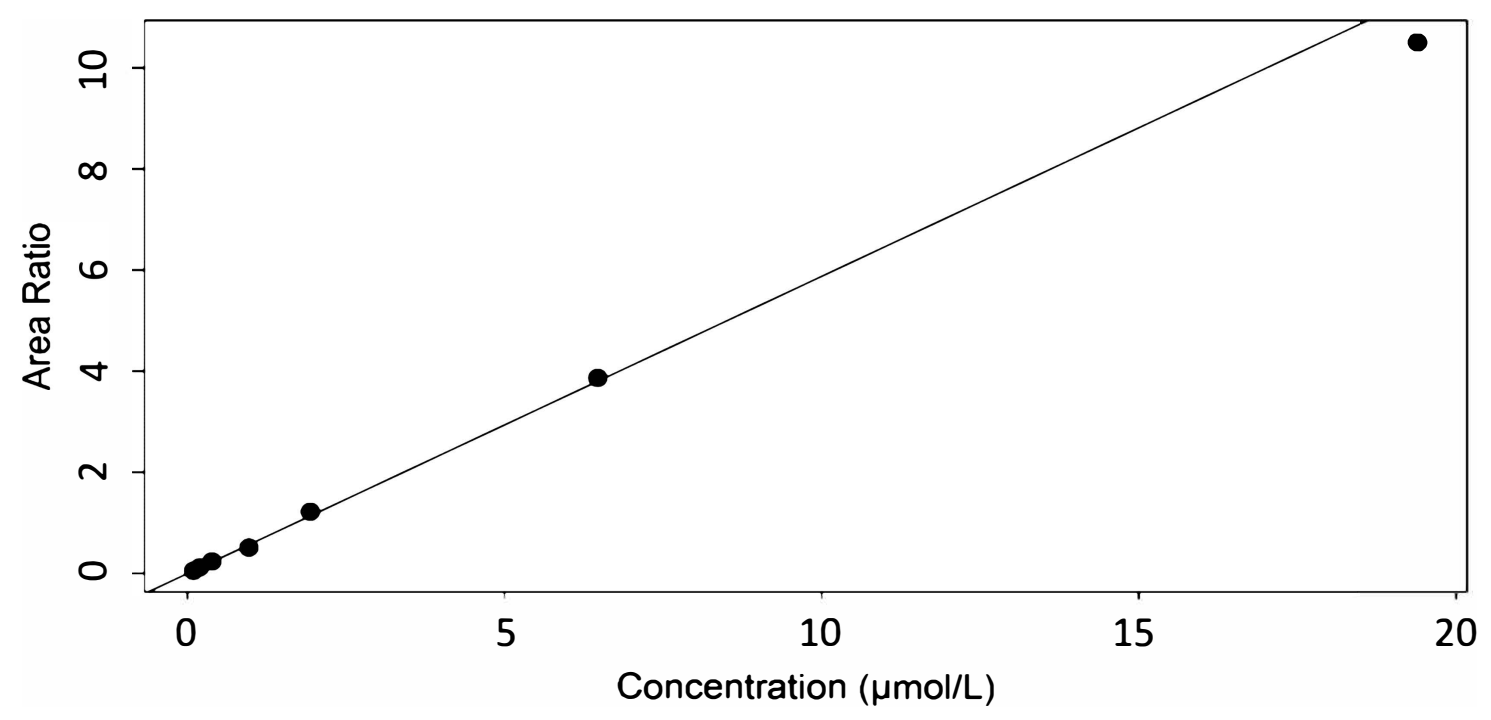

Fig. (4). Representative calibration curve of K-868 obtained in $0.3 \mathrm{~mol} / \mathrm{L}$ aqueous perchloric acid. The means of 2 replicate measurements were used for the quantification of K-868 in the in vivo samples. The equation of the fitted line is $\mathrm{y}=0.3967 \mathrm{x}-0.0112$, the determination coefficient is 0.9957 .
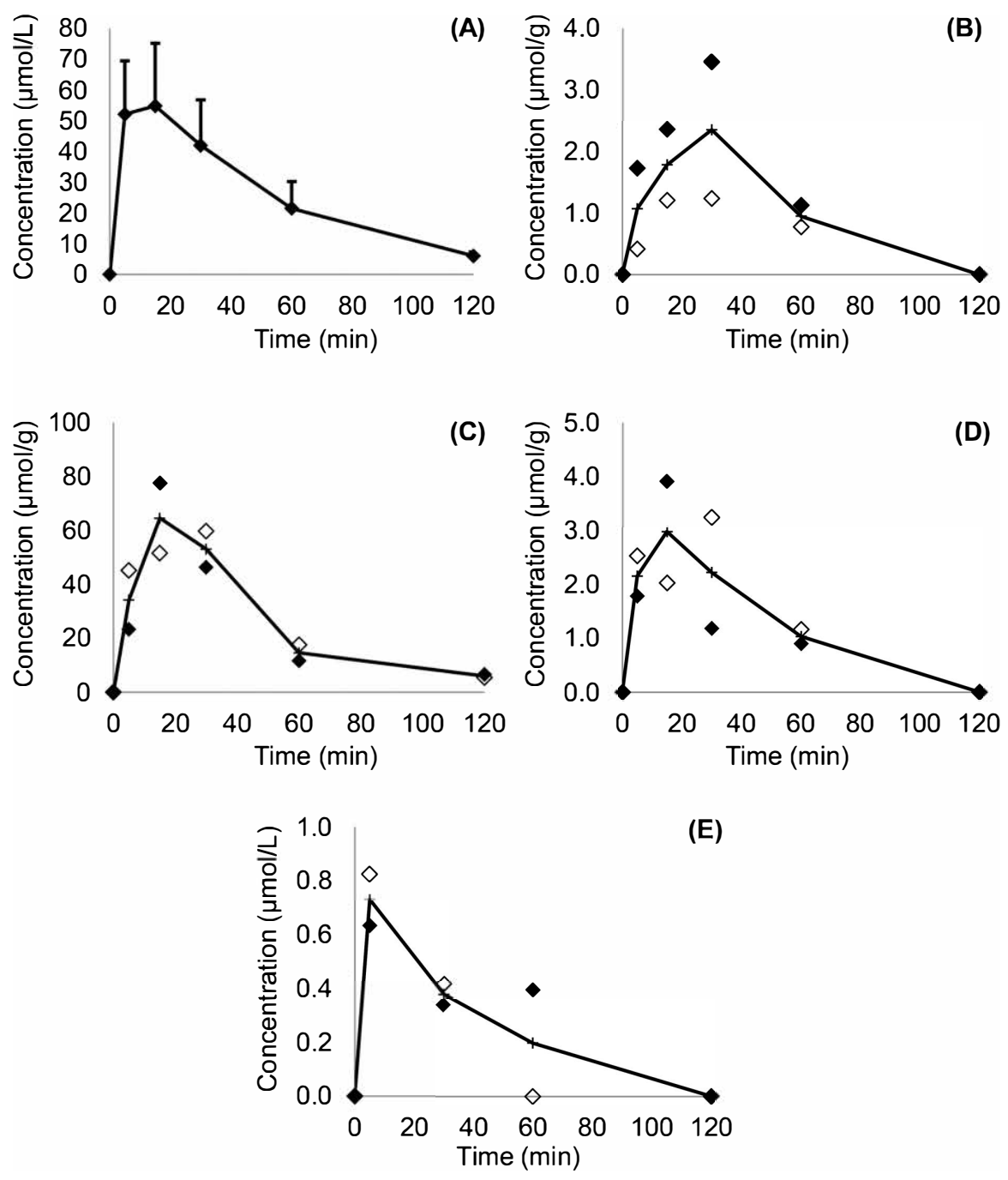

Fig. (5). Time-dependence of K-868 levels following i.m. treatment with $30 \mu$ mol K-868 in $(\mathbf{A})$ serum $(n=6),(\mathbf{B})$ the eyes $(n=2),(\mathbf{C})$ kidneys $(n=2)$, (D) lungs $(\mathrm{n}=2)$, and $(\mathbf{E})$ tear $(\mathrm{n}=2)$. Means and standard deviations are plotted for serum. The numerical data are provided in Table $\mathbf{2}$. 
Table 3. 120-minute areas under the concentration-time curve $\left(\mathrm{AUC}_{0-120}\right)$ of $\mathrm{K}-868$ in body fluids and in solid organs. The results of $n=2$ experiments are shown, except for serum $(n=6)$ for which mean \pm standard deviation is displayed.

\begin{tabular}{|c|c|c|c|c|}
\hline Bodily Fluid/Solid Organ & \multicolumn{2}{|c|}{$\mathbf{A U C _ { 0 - 1 2 0 }}$} & \multicolumn{2}{|c|}{$\mathrm{AUC}_{0-120}$ (Tissue)/AUC $\mathbf{A O}_{0-120}$ (Serum) } \\
\hline & \multicolumn{2}{|c|}{ Mean \pm Standard Deviation } & \multicolumn{2}{|c|}{ Mean } \\
\hline Serum, $\left(\mu \mathrm{mol} \mathrm{min} \mathrm{L}^{-1}\right)$ & \multicolumn{2}{|c|}{$3165 \pm 1006$} & \multicolumn{2}{|c|}{$100 \%$} \\
\hline Brain $\left(\mu \mathrm{mol} \mathrm{min} \mathrm{g}^{-1}\right)$ & \multicolumn{2}{|c|}{ Detected, but not quantitated in 10 samples, not detected in 20 samples, } & \multicolumn{2}{|c|}{$0 \%$ (not quantitated) } \\
\hline Bodily Fluid/Solid Organ & Animal 1 & Animal 2 & Animal 1 & Animal 2 \\
\hline Cerebrospinal fluid $\left(\mu \mathrm{mol} \mathrm{min} \mathrm{L}^{-1}\right)$ & not detected & not detected & $0 \%$ & $0 \%$ \\
\hline Eye $\left(\mu \mathrm{mol} \mathrm{min} \mathrm{g}^{-1}\right)$ & 80.4 & 171 & $3.0 \%$ & $5.5 \%$ \\
\hline Kidney $\left(\mu \mathrm{mol} \mathrm{min} \mathrm{\textrm {g } ^ { - 1 } )}\right.$ & 2908 & 3284 & $109 \%$ & $106 \%$ \\
\hline Liver $\left(\mu \mathrm{mol} \mathrm{min} \mathrm{g}^{-1}\right)$ & not detected & not detected & $0 \%$ & $0 \%$ \\
\hline Lung $\left(\mu \mathrm{mol} \min \mathrm{g}^{-1}\right)$ & 129 & 169 & $4.8 \%$ & $5.5 \%$ \\
\hline Tear $\left(\mu \mathrm{mol} \mathrm{min} \mathrm{L}^{-1}\right)$ & 36.5 & 23.8 & $1.4 \%$ & $0.8 \%$ \\
\hline Testis $\left(\mu \mathrm{mol} \min ^{-1}\right)$ & not detected & not detected & $0 \%$ & $0 \%$ \\
\hline
\end{tabular}

\section{DISCUSSION}

The presented results were obtained in a preliminary in vivo pharmacokinetic study of $\mathrm{K}-868$, a novel candidate antidote against poisoning with organophosphorus substances. K-868 is an ionic entity showing very close similarity to several other K-oximes both in terms of its extreme hydrophilicity and its topological polar surface area of about 85 $\AA^{2}$ (Table 1). It must be noted that its solubility in water is, nevertheless, limited.

$30 \mu \mathrm{mol}$ of K-868 was administered. Often the target dose in preliminary in vivo pharmacokinetic experiments conducted with $\mathrm{K}$-oximes is $10 \%$ of the intramuscular $\mathrm{LD}_{50}$. Due to the poor solubility of K-868 in aqueous media, however, the intramuscular $\mathrm{LD}_{50}$ could not be established. Therefore, the aim was to obtain a solution of $\mathrm{K}-868$ at a concentration close to saturation.

Rats have been employed successfully for establishing the experimental pharmacokinetic and toxic properties of several K-oximes [ 30 - 36]. Nevertheless, much less information is available on the fate of these substances in humans [37, 38]. It may be argued from a strictly scientific perspective that a larger number of animals should have been used for the presented evaluation. However, the number of animals employed (30) has allowed the inference of the major pharmacokinetic properties of K-868, and the authors considered it unethical to include more animals at this early stage just to be able to talk in statistical terms without gaining novel information. . Nevertheless, sufficiently designed comparative in vivo experiments need to be conducted in the future in order to judge the ultimate value of K-868 as an antidote.

K-868 showed excellent in vitro reactivation ability for $\mathrm{BuChE}$ inhibited by various nerve gases [24]. Considering the prolonged presence and effects of certain nerve agents (e.g., tabun, soman, VX, or Novichok) [39, 40], the combination therapy of short-acting antidotes and cholinesterase reactivators with slow elimination can offer important advantages. Pyridinium aldoxime reactivators are ionic entities with negative $\log \mathrm{P}$ values due to the presence of two quaternary nitrogen atoms in the structure, which generally results in their rapid elimination. The presence of two chlorine atoms, however, seems to have a major impact on the pharmacokinetic behavior of these substances by slowing their elimination. This is in concordance with the fact that several bis-chlorine organic compounds are used in medical practice with a wide range of clinical indications and that the presence and location of the two chlorine atoms in their structures are crucial in view of their pharmacological profiles [23].

The penetration of K-868 into the major eliminating organs (kidneys and liver), the main target organs for organophosphates (brain, eyes, and lungs) [41], and organs separated from the systemic circulation by barriers (brains and testes) was investigated. Intramuscular bolus administration was chosen because this is the most important route in the case of the real-life administration of any antidote against organophosphate poisoning [35]. A sharp contrast can be made between the pharmacokinetics of K-868 and that of K-347, a nonhalogenated bis-aromatic monopyridinium aldoxime also tested recently as a candidate cholinesterase reactivator and employed in this study as an internal standard [20]. Following its administration, K-347 attains maximum concentrations in blood within 15 min which subsequently displays a rapid decline. In fact, the experiments with K-347 confirm the wellknown disadvantage, i.e., the very rapid excretion of monopyridinium aldoxime cholinesterase reactivators including pralidoxime, obidoxime, and HI-6 (asoxime). The addition of a second pyridinium ring to the structure has no effect on the quick appearance of the substance in the systemic circulation.After an i.m bolus injection, similarly to other related entities, K-868 appeared in blood at 5 minutes and reached its peak within 15-30 minutes. However, the decline of its concentrations was slow, and the substance could still be detected in the circulation at 120 minutes. This decline is even slower than that of K-203, a nonhalogenated bis-pyridinium aldoxime with an outstanding efficiency against the important nerve agent tabun. K-203 also reached peak concentrations in 15-minute blood samples but displayed a faster monotonous decline to $25 \%$ of its maximum by 60 minutes $[14,22]$. In pigs, the times to reach peak concentrations of K-27 and K-203 were very similar ( $19 \pm 5$ and $22 \pm 3 \mathrm{~min}$, respectively). After these maxima, declines at a constant rate were observed after a single 
intramuscular dose. It must be noted that K-203 [19, 22, 26], K-27 [10, 27], and K-48 [29], which all show a similarity in their structures to that of K-868, penetrate through the bloodbrain-barrier. K-868 is the halogenated derivative of $\mathrm{K}-27$, and the presence of the two chlorine substituents seems to yield essential differences, assumably as a result of the enlargement of its total molecular surface, which leads to its decreased filtration by the kidneys and its inability to penetrate through the blood-brain barrier.

Our results demonstrate that K-868 is not extracted by the liver but is excreted renally. Therefore, we assume that the prolonged presence of this substance in the body primarily results from the limited eliminating capacity of the kidneys, which, along with its observed distribution to certain peripheral organs such as the lungs, eyes, and tear, could be beneficial in terms of its action as an antidote. This benefit may be explored further by optimizing the dosing regimen of K-868. These properties are also closest to those of the other two monochlorinated bis-pyridinium aldoximes K-867 and K-870, which were not found in the liver, penetrated through the blood-brain barrier to a minimal extent but reached appreciable concentrations in the lungs and the kidneys [13]. Nonhalogenated bis-aromatic monopyridinium (e.g., K-347) and bis-pyridinium (e.g., K-117 and K-127) aldoximes have markedly different properties: they are eliminated by the liver, can be detected in the central nervous system in higher concentrations, and are found in the testes [20, 21]. It must be noted that the pharmacokinetics of the most closely related non-halogenated analog K-27 remains to be investigated in similar detail.

The limited capacity of the renal excretion of K-868 causes its elimination to be dose-dependent. This issue has important consequences on other pharmacokinetic parameters, warranting their estimation as a function of K-868 doses. Experiments are also being conducted to clarify the extent to which the absorption of K-868 from i.m. bolus injections depends on the administered quantities. Currently, it can be inferred that substantial research is required to comprehensively elaborate the pharmacokinetics of K-868, as well as to make quantitative comparisons with the established parameters of other Koximes.

Recent improvement of bioanalytical chromatography has had a profound impact on in vivo experimental pharmacokinetic studies of pyridinium aldoximes (Table 1). Earlier methods, such as those employed for the determination of K-27, K-48, and K-203, relied on separations with long (250 $\mathrm{mm}$ ) stationary phases packed with fully porous particles with an average diameter of $5 \mu \mathrm{m}$. The increased separation efficiency allowed by core-shell particle technology and the availability of short, narrow-bore analytical columns has led to improved sensitivity and considerably shorter run times. The affordable costs of the employed method pave the way to the large-scale investigation and comparison of the pharmacokinetic properties of pyridinium aldoxime cholinesterase reactivators.

A limitation of this work is the lack of data on the distribution of K-868 in the cardiac muscle. Research is planned indeed to clarify whether K-868 could counteract the myocardial effects of organophosphorus agents. Another limitation is the small number of animals used in the parallel experiments. Nevertheless, the results obtained in these experiments were convincing in terms of which organs K-868 would distribute into, as well as of the key route of its elimination. The involvement of more animals would not have added important information at this stage. Further research is needed for the elucidation of the relationship between various doses and the exposure to K-868 in the systemic circulation and in peripheral spaces.

\section{CONCLUSION}

K-868 shows unique pharmacokinetic properties compared to those of other pyridinium aldoxime cholinesterase reactivators. Most importantly, it has a prolonged presence in the circulation, opening a new deal to produce slowly eliminating antidotes. These properties can be attributed to the presence of two chlorine atoms in the structure. The pharmacokinetics of other pyridinium aldoximes with an npentyl bridge and/or an aromatic ring condensed to the pyridinium ring are in several aspects different, making K-868 a real alternative to other candidate antidotes against poisoning with organophosphorus substances.

\section{ETHICS APPROVAL AND CONSENT TO PARTI- CIPATE}

This study was approved by the Local Committee of Animal Welfare (Permission Number: PE/EA/385-7/2018).

\section{HUMAN AND ANIMAL RIGHTS}

No humans were used for studies that are the basis of this research. All steps of animal handling, treatment procedures, and sample preparation conformed to the 2010/63/EU regulation on the well-being of experimental animals.

\section{CONSENT FOR PUBLICATION}

Not applicable.

\section{AVAILABILITY OF DATA AND MATERIALS}

The data sets used during the current study can be provided from the corresponding author [G.K] , upon reasonable request.

\section{FUNDING}

This research has financially been sponsored by the grant NN126968 of the Hungarian National Agency for Research and Development and by the Ministry of Education, Youth and Sports of the Czech Republic (No. 8F170049).

\section{CONFLICT OF INTEREST}

Dr. Ernest Adeghate is the Editorial Board Member for the journal The open Medicinal Chemistry Journal.

\section{ACKNOWLEDGEMENTS}

Professor Kamil Musilek (Department of Chemistry, University of Hradec Kralove, Rokitanskeho 62, 500 03, Hradec Kralove, Czech Republic) synthetized and sent us all the K-compounds used in this project. Dr. Dóra Bogdán, Ph.D. 
and Dr. István Mándity, Ph.D. are gratefully acknowledged for performing the melting point measurements at the Department of Organic Chemistry, Faculty of Pharmacy, Semmelweis University. Advice, cooperation, and technical assistance of Ms. Györgyike Guth, Ms. Krisztina Kecskés, Ms. Bogi Szalacsi, Mr. János Horváth, Mr. András Keglevich, and Mr. Zoltán Szimrok are appreciated.

\section{REFERENCES}

[1] Muñoz-Quezada, M.T.; Lucero, B.A.; Iglesias, V.P.; Muñoz, M.P.; Cornejo, C.A.; Achu, E.; Baumert, B.; Hanchey, A.; Concha, C.; Brito, A.M.; Villalobos, M. Chronic exposure to organophosphate (OP) pesticides and neuropsychological functioning in farm workers: A review. Int. J. Occup. Environ. Health, 2016, 22(1), 68-79. [http://dx.doi.org/10.1080/10773525.2015.1123848]

[PMID: 27128815]

[2] Gunnell, D.; Knipe, D.; Chang, S-S.; Pearson, M.; Konradsen, F.; Lee, W.J.; Eddleston, M. Prevention of suicide with regulations aimed at restricting access to highly hazardous pesticides: a systematic review of the international evidence. Lancet Glob. Health, 2017, 5(10), e1026-e1037.

[http://dx.doi.org/10.1016/S2214-109X(17)30299-1] [PMID: 28807587]

[3] Okumura, T.; Suzuki, K.; Fukuda, A.; Kohama, A.; Takasu, N.; Ishimatsu, S.; Hinohara, S. The Tokyo subway sarin attack: Disaster management, Part 1: Community emergency response. Acad. Emerg. Med., 1998, 5(6), 613-617.

[http://dx.doi.org/10.1111/j.1553-2712.1998.tb02470.x] [PMID: 9660289]

[4] John, H.; van der Schans, M.J.; Koller, M.; Spruit, H.E.T.; Worek, F.; Thiermann, H.; Noort, D. Fatal sarin poisoning in Syria 2013: Forensic verification within an international laboratory network. Forensic Toxicol., 2018, 36(1), 61-71. [http://dx.doi.org/10.1007/s11419-017-0376-7] [PMID: 29367863]

[5] Droste, D.J.; Shelley, M.L.; Gearhart, J.M.; Kempisty, D.M. A systems dynamics approach to the efficacy of oxime therapy for mild exposure to sarin gas. Am. J. Disaster Med., 2016, 11(2), 89-118. [http://dx.doi.org/10.5055/ajdm.2016.0229] [PMID: 28102531]

[6] Chai, P.R.; Hayes, B.D.; Erickson, T.B.; Boyer, E.W. Novichok agents: A historical, current, and toxicological perspective. Toxicol. Commun., 2018, 2(1), 45-48.

[http://dx.doi.org/10.1080/24734306.2018.1475151] [PMID: 30003185]

[7] Petroianu, G.A.; Kalász, H. Comparison of the ability of pyridinium aldoximes to reactivate human RPC cholinesterases inhibited by ethyland methyl paraoxone. Curr. Org. Chem., 2007, 11, 1624-1634. [http://dx.doi.org/10.2174/138527207783221183]

[8] Petroianu, G.A. Pralidoxime rescues both muscarinic and nicotinic systems. Anesth. Analg., 2005, 101(3), 926-927.

[http://dx.doi.org/10.1213/01.ANE.0000173672.80018.D9] [PMID: 16116023]

[9] Kalász, H.; Nurulain, S.M.; Veress, G.; Antus, S.; Darvas, F.; Adeghate, E.; Adem, A.; Hashemi, F.; Tekes, K. Mini review on blood-brain barrier penetration of pyridinium aldoximes. J. Appl. Toxicol., 2015, 35(2), 116-123.

[http://dx.doi.org/10.1002/jat.3048] [PMID: 25291712]

[10] Tekes, K.; Hasan, M.Y.; Sheen, R. HPLC determination of the serum concentration of K-27, a novel oxime-type cholinesterase reactivator. J. Chromatogr. A, 2006, 1122, 84-87.

[http://dx.doi.org/10.1016/j.chroma.2006.04.016] [PMID: 16690067]

[11] Kalász, H.; Tekes, K.; Pöstényi, Z. Pharmacokinetics of selegiline in a rabbit model. Lett. Drug Design Dev., 2016, 13, 752-756. [http://dx.doi.org/10.2174/1570180813666160125224604]

[12] Kalász, H.; Karvaly, G.; Musilek, K. Dose-dependent tissue distribution of K-117, a bis-pyridinium aldoxime in rats. Open Med. Chem. J., 2019, 13, 1-6.

[http://dx.doi.org/10.2174/1874104501913010001]

[13] Kalász, H.; Szimrók, Z.; Karvaly, G.; Adeghate, J.; Tekes, K. Pharmacokinetics of two chlorine-substituted bis-pyridinium monoaldoximes with regenerating effect on butyrylcholinesterase. Molecules, 2020, 25(5), 1250-1259. [http://dx.doi.org/10.3390/molecules25051250] [PMID: 32164301]

[14] Kassa, J.; Karasová, J.Z.; Kuča, K. Comparison of the neuroprotective effects of a novel bis-pyridinium oxime KR-22934 with the oxime
K-203 and obidoxime in tabun-poisoned male rats. J. Appl. Biomed., 2014, 12, 111-117.

[http://dx.doi.org/10.1016/j.jab.2013.04.002]

[15] Kassa, J.; Karasova, J.Z.; Pavlikova, R.; Musilek, K.; Kuca, K.; Bajgar, J.; Jung, Y.S. A comparison of reactivating and therapeutic efficacy of bispyridinium acetylcholinesterase reactivator KR-22934 with the oxime K203 and commonly used oximes (obidoxime, trimedoxime, HI-6) in tabun-poisoned rats and mice. Toxicol. Mech. Methods, 2011, 21(3), 241-245.

[http://dx.doi.org/10.3109/15376516.2010.538750] [PMID: 21142778]

[16] Jun, D.; Musilova, L.; Pohanka, M.; Jung, Y.S.; Bostik, P.; Kuca, K. Reactivation of human acetylcholinesterase and butyrylcholinesterase inhibited by leptophos-oxon with different oxime reactivators in vitro. Int. J. Mol. Sci., 2010, $11(8), 2856-2863$.

[http://dx.doi.org/10.3390/ijms11082856] [PMID: 21152278]

[17] Winter, M.; Wille, T.; Musilek, K.; Kuca, K.; Thiermann, H.; Worek, F. Investigation of the reactivation kinetics of a large series of bispyridinium oximes with organophosphate-inhibited human acetylcholinesterase. Toxicol. Lett., 2016, 244, 136-142. [http://dx.doi.org/10.1016/j.toxlet.2015.07.007] [PMID: 26210933]

[18] Karasova, J.Z.; Kassa, J.; Musilek, K.; Pohanka, M.; Novotny, L.; Kuca, K. Effect of seven newly synthesized and currently available oxime cholinesterase reactivators on cyclosarin-intoxicated rats. Int. J. Mol. Sci., 2009, 10(7), 3065-3075.

[http://dx.doi.org/10.3390/ijms10073065] [PMID: 19742125]

[19] Kuča, K.; Musilek, K.; Jun, D.; Zdarova-Karasova, J.; Nepovimova, E.; Soukup, O.; Hrabinova, M.; Mikler, J.; Franca, T.C.C.; Da Cunha, E.F.F.; De Castro, A.A.; Valis, M.; Ramalho, T.C. A newly developed oxime $\mathrm{K} 203$ is the most effective reactivator of tabun-inhibited acetylcholinesterase. BMC Pharmacol. Toxicol., 2018, 19(1), 8. [http://dx.doi.org/10.1186/s40360-018-0196-3] [PMID: 29467029]

[20] Kalász, H.; Karvaly, G.; Szimrók, F. Pharmacokinetics of a bispyridinium-mono-aldoxime (K-347), a potential antidote in organophosphate poisonings. Open Med. Chem. J., 2020, 14, 3-11. [http://dx.doi.org/10.2174/1874104502014010099]

[21] Tekes, K.; Karvaly, G.; Nurulain, S.; Kuca, K.; Musilek, K.; Adeghate, E.; Jung, Y.S.; Kalász, H. Pharmacokinetics of K117 and K127, two novel antidote candidates to treat Tabun poisoning. Chem. Biol. Interact., 2019, 310, 108737.

[http://dx.doi.org/10.1016/j.cbi.2019.108737] [PMID: 31279792]

[22] Kalász, H.; Laufer, R.; Szegi, P. HPLC study of the pharmacokinetics of K-203. Acta Chromatogr., 2008, 20, 575-584.

[http://dx.doi.org/10.1556/AChrom.20.2008.4.4]

[23] Brunton, L.L.; Lazo, J.S.; Parker, K.L., Eds.; Goodman \& Gilman's The Pharmacological Basis of Therapeutics, 11th ed; Mc-Graw-Hill: New York, 2005.

[24] Zorbaz, T.; Malinak, D.; Kuca, K.; Musilek, K.; Kovarik, Z. Butyrylcholinesterase inhibited by nerve agents is efficiently reactivated with chlorinated pyridinium oximes. Chem. Biol. Interact., 2019, 307, 16-20.

[http://dx.doi.org/10.1016/j.cbi.2019.04.020] [PMID: 31004594]

[25] Karvaly, G.; Tekes, K.; Szimrók, Z. A fieldable, high-throughput, cost-efficient high performance liquid chromatography-ultraviolet detection (HPLC-UV) method for the quantitation of bis-pyridinium quaternary aldoxime cholinesterase reactivators in blood. Acta Chromatogr., 2021, 33, 134-144.

[http://dx.doi.org/10.1556/1326.2020.00781]

[26] Szegi, P.; Kalász, H.; Laufer, R.; Kuca, K.; Tekes, K. Pyridinium aldoxime analysis by HPLC: the method for studies on pharmacokinetics and stability. Anal. Bioanal. Chem., 2010, 397(2), 579-586.

[http://dx.doi.org/10.1007/s00216-010-3635-6] [PMID: 20349225]

[27] Gyenge, M.; Kalász, H.; Petroianu, G.A.; Laufer, R.; Kuca, K.; Tekes, K. Measurement of K-27, an oxime-type cholinesterase reactivator by high-performance liquid chromatography with electrochemical detection from different biological samples. J. Chromatogr. A, 2007, 1161(1-2), 146-151.

[http://dx.doi.org/10.1016/j.chroma.2007.05.106] [PMID: 17603065]

[28] Kassa, J.; Karasova, J.Z.; Kuca, K.; Musilek, K. A comparison of the reactivating and therapeutic efficacy of newly developed oximes (K347, K628) with commonly used oximes (obidoxime, HI-6) against tabun in rats and mice. Drug Chem. Toxicol., 2010, 33(3), 227-232. [http://dx.doi.org/10.3109/01480540903483409] [PMID: 20429807]

[29] Kalász, H.; Hasan, M.Y.; Sheen, R.; Kuča, K.; Petroianu, G.; Ludányi, K.; Gergely, A.; Tekes, K. HPLC analysis of K-48 concentration in plasma. Anal. Bioanal. Chem., 2006, 385(6), 1062-1067. [http://dx.doi.org/10.1007/s00216-006-0490-6] [PMID: 16763789] 
[30] Petroianu, G.A.; Nurulain, S.M.; Nagelkerke, N.; Al-Sultan, M.A.; Kuca, K.; Kassa, J. Five oximes (K-27, K-33, K-48, BI-6 and methoxime) in comparison with pralidoxime: survival in rats exposed to the organophosphate paraoxon. J. Appl. Toxicol., 2006, 26(3), 262-268.

[http://dx.doi.org/10.1002/jat.1143] [PMID: 16583462]

[31] Lorke, D.E.; Hasan, M.Y.; Nurulain, S.M.; Kuca, K.; Schmitt, A.; Petroianu, G.A. Efficacy of two new asymmetric bispyridinium oximes (K-27 and K-48) in rats exposed to diisopropylfluorophosphate: comparison with pralidoxime, obidoxime, trimedoxime, methoxime, and HI-6. Toxicol. Mech. Methods, 2009, 19(4), 327-333.

[http://dx.doi.org/10.1080/15376510902798695] [PMID: 19778224]

[32] Kassa, J.; Karasova, J.Z.; Sepsova, V.; Caisberger, F.; Bajgar, J. A comparison of the reactivating and therapeutic efficacy of chosen combinations of oximes with individual oximes against VX in rats and mice. Int. J. Toxicol., 2011, 30(5), 562-567.

[http://dx.doi.org/10.1177/1091581811415294] [PMID: 22013137]

[33] Caisberger, F.; Pejchal, J.; Misik, J.; Kassa, J.; Valis, M.; Kuca, K. The benefit of combinations of oximes for the ability of antidotal treatment to counteract sarin-induced brain damage in rats. BMC Pharmacol. Toxicol., 2018, $19(1), 35$.

[http://dx.doi.org/10.1186/s40360-018-0227-0] [PMID: 29954446]

[34] Lorke, D.E.; Nurulain, S.M.; Hasan, M.Y.; Kuča, K.; Petroianu, G.A. Experimental and established oximes as pretreatment before acute exposure to azinphos-methyl. Int. J. Mol. Sci., 2021, 22(6), 3072. [http://dx.doi.org/10.3390/ijms22063072] [PMID: 33802843]

[35] Jaćević, V.; Nepovimova, E.; Kuča, K. Toxic injury to muscle tisse of rats following acute oximes exposure. Sci. Rep., 2019, 9(1), 1457. [http://dx.doi.org/10.1038/s41598-018-37837-4] [PMID: 30728420]

[36] Jaćević, V.; Nepovimova, E.; Kuča, K. Acute toxic injuries of rat's visceral tissues induced by different oximes. Sci. Rep., 2019, 9(1), 16425 .

[http://dx.doi.org/10.1038/s41598-019-52768-4] [PMID: 31712702]

[37] Lorke, D.E.; Hasan, M.Y.; Arafat, K.; Kuca, K.; Musilek, K.; Schmitt, A.; Petroianu, G.A. In vitro oxime protection of human red blood cell acetylcholinesterase inhibited by diisopropyl-fluorophosphate. J. Appl. Toxicol., 2008, 28(4), 422-429.

[http://dx.doi.org/10.1002/jat.1344] [PMID: 18344198]

[38] Amitai, G.; Plotnikov, A.; Chapman, S.; Lazar, S.; Gez, R.; Loewenthal, D.; Shurrush, K.A.; Cohen, G.; Solmesky, L.J.; Barr, H.; Russell, A.J. Non-quaternary oximes detoxify nerve agents and reactivate nerve agent-inhibited human butyrylcholinesterase. Commun. Biol., 2021, 4(1), 573.

[http://dx.doi.org/10.1038/s42003-021-02061-w] [PMID: 33990679]

[39] Ganesan, K.; Raza, S.K.; Vijayaraghavan, R. Chemical warfare agents. J. Pharm. Bioallied Sci., 2010, 2(3), 166-178.

[http://dx.doi.org/10.4103/0975-7406.68498] [PMID: 21829312]

[40] Nepovimova, E.; Kuca, K. Chemical warfare agent NOVICHOK mini-review of available data. Food Chem. Toxicol., 2018, 121, 343-350.

[http://dx.doi.org/10.1016/j.fct.2018.09.015] [PMID: 30213549]

[41] Peter, J.V.; Sudarsan, T.I.; Moran, J.L. Clinical features of organophosphate poisoning: A review of different classification systems and approaches. Indian J. Crit. Care Med., 2014, 18(11), $735-745$.

[http://dx.doi.org/10.4103/0972-5229.144017] [PMID: 25425841]

\section{C) 2021 Kalász et al.}

This is an open access article distributed under the terms of the Creative Commons Attribution 4.0 International Public License (CC-BY 4.0), a copy of which is available at: https://creativecommons.org/licenses/by/4.0/legalcode. This license permits unrestricted use, distribution, and reproduction in any medium, provided the original author and source are credited. 